\title{
Methods for screening and prevention of HPV infection - a retrospective study
}

\author{
Catalina Diana Stanica', Romina Marina Sima', Raluca Gabriela Ioan', \\ Constantin Dimitrie Nanu ${ }^{1}$, Ilinca Neacsu ${ }^{2,3}$, Adrian Neacsu ${ }^{1}$ \\ ${ }^{1}$ Department of Obstetrics and Gynecology, \\ "Carol Davila" University of Medicine and Pharmacy, Bucharest, Romania \\ 2Department of Pathology, "Binafarm", Bucharest, Romania \\ ${ }^{3}$ Translational School of Biological Sciences, Faculty of Biology, Medicine and Health, \\ The University of Manchester, United Kingdom
}

\begin{abstract}
Worldwide, cervical cancer ranks 4th in frequency in the female population, with about half of the cases being fatal. In Romania, it is the second type of cancer found in women, after breast cancer and the main cause of cancer mortality in patients aged between 15 and 44 years. The main cause of this type of cancer is human papilloma virus (HPV) infection.

Although HPV is very widespread (> $85 \%$ ), progression to cervical cancer is relatively rare. In countries that have implemented cervical screening programs, the incidence and mortality caused by this pathology have decreased by $50-75 \%$. Also, the emergence of vaccines against the most common strains of oncogenic HPV and the implementation of vaccination programs will bring additional benefits in preventing cervical cancer.

This paper presents the results of a retrospective study, performed on a number of 92 patients, which aimed to know the distribution of different HPV genotypes, their impact on the cervical epithelium, the degree of access to the national screening program, and openness to anti HPV vaccination.
\end{abstract}

Keywords: HPV infection, cervical cancer, HPV screening, HPV vaccination

\section{INTRODUCTION}

Cervical cancer was the fourth leading cause of cancer in women worldwide, accounting for $3.2 \%$ of all newly diagnosed cancers. The highest incidence, as well as the highest mortality from cervical cancer, is found in underdeveloped countries $(1,2)$ and mainly affects women of reproductive age who have never had a Babes-Papanicolau examination. This is due to the inefficiency of screening programs and the lack of availability of vaccination (3).

The main cause of cervical cancer is human papilloma virus (HPV) infection, virtually all cases of cervical cancer (99\%) have been associated with genital HPV infection. HPV is also implicated in the occurrence of other types of anogenital cancer: anal, vul- var, vaginal, oropharyngeal and penile neoplasm, as well as benign conditions, such as acuminate warts (4-6).

The HPV family has over 200 viral strains that, depending on their oncological pathogenesis, can be classified into pathogens with high or low oncological risk. Infections with low oncological risk are often silent and generate cytological alterations such as cervical grade 1 neoplasms (CIN 1) or low-grade squamous intraepithelial lesions (LSIL). Infections with an increased risk of oncology, which are less common, can progress to high-grade squamous lesions (CIN 2-3, HSIL) and cervical cancer. Some of these low-risk strains are associated with tumors located in the anogenital area. HPV infections type 6 
and 11 are very rarely associated with neoplastic lesions, being generally responsible for acuminate warts (7).

A considerable part of HPV infections are selflimiting. Most are asymptomatic (70-90\%) and can resolve in a year or two. A small part of these infections $(5-10 \%)$ become persistent and cause precancerous lesions that progress to malignancy. The period in which an HPV infection can progress to invasive carcinoma is $7-10$ years $(8-10)$.

Vaccination programs associated with vaccination are the best approach for protection against cervical cancer. Periodical Babes-Papanicolaou testing can detect precancerous lesions, or carcinoma in situ, as well as HPV genotyping.

Due to these practices, mortality from cervical cancer has decreased in recent decades by more than $30 \%$ in Europe and by more than $50 \%$ worldwide $(11,12)$.

In addition to screening programs, the prevention of HPV infection is based on vaccination. The 3 currently marketed vaccines, bi-, tetra-, and nonavalent, are very effective against HPV 6, 11, 16 and 18, the most common genotypes encountered. The protection for cervical cancer given by the nonvalent vaccine can reach $90 \%(13,14)$.

HPV vaccination has been adopted by many countries worldwide, and its effectiveness has already been demonstrated in developed countries, where it has led to a $60 \%$ reduction in precancerous lesions compared to the control group (unvaccinated) $(15,16)$.

Screening for cervical cancer is recommended for both unvaccinated and vaccinated women who may become infected with strains other than those for which they have acquired immunity (17).

\section{MATERIAL AND METHOD}

This paper presents the results of a retrospective study, conducted in a private clinic, on a number of 92 patients during 2020 .

The aim was to know the distribution of different HPV genotypes, their impact on the cervical epithelium, the degree of access to the national screening program, as well as the openness to HPV vaccination.

We included patients who had: a positive HPV genotyping test for at least one strain, Babes-Papanicolu examination and more than one presentation in the clinic during the study.
All data obtained were processed while maintaining the confidentiality of patients' personal data.

The data were collected from patient tracking sheets, being processed in Microsoft Excel. We retained information about: the reason for the presentation in the clinic, age, parity, lifestyle habits (number of sexual partners, tobacco use, use of estroprogestative contraceptives or condoms), HPV vaccination, investigations and treatments performed.

\section{RESULTS}

Reasons for presentation at the clinic included: genital discomfort, dyspareunia and regular checkups.

One of the inclusion criteria was the diagnosis of at least one HPV strain. In $21(22.82 \%)$ of the patients, only one strain was highlighted, the vast majority having two or more strains. Among the genotypes with high oncogenic risk, strains 16, 18, 31, 33, 45, 51 and 52 were identified most frequently; and of those with low risk the most common were $6,11,42$, 44,54 . In the case of highlighting several genotypes, the associations were diverse, including both lowrisk and high-risk strains. In addition to HPV, 53 (57.60\%) patients also had other types of genital infections, including Candida albicans, Trichomonas vaginalis, Neisseria gonorrhoeae, Gardnerella vaginalis, Herpes simplex type 2 (HSV-2), Streptococcus beta-hemolytic (Streptococcus agalactiae), Staphylococcus aureus.

Another inclusion criterion was the presence of at least one Babes-Papanicolau exam. Of the 92 patients included in the studies, 68 (73.91\%) had classical cytology, per slide, and 24 (26.08\%) in liquid medium. Being included in the national screening program for cervical cancer, the clinic includes all patients between the ages of 24 and 64 in the program. For this reason, $23(25 \%)$ patients benefited for the first time from a vaginal cytology examination, of which 18 $(19,56 \%)$ came from rural areas and $5(5.43 \%)$ from urban areas.

The results of the Babes-Papanicolau exam (BPN) were $44(47.8 \%)$ normal and $48(52.17 \%)$ with changes. The results are presented in Table 1.

The age of the patients included in the study was between 18 and 64 years, according to table 2. Although the screening program for cervical cancer is aimed at women between 24 and 64 years, we included in the study the age group 18-24 years, comprising 
16 patients who went to the clinic for mixed genital infections, including HPV and HSV-2. All these patients were smokers and did not use any contraceptive (barrier, or hormonal).

TABLE 1. Babes-Papanicolau (BPN) exam results

\begin{tabular}{|l|c|c|}
\hline \multicolumn{1}{|c|}{ BPN exam } & $\begin{array}{c}\text { Number of } \\
\text { patients }\end{array}$ & Percentages \\
\hline No changes & 44 & $47.8 \%$ \\
\hline $\begin{array}{l}\text { ASC-US (atypical squamous cells } \\
\text { of undetermined significance) }\end{array}$ & 16 & $17.39 \%$ \\
\hline $\begin{array}{l}\text { LSIL (low-grade squamous } \\
\text { intraepithelial lesion) }\end{array}$ & 14 & $15.21 \%$ \\
\hline $\begin{array}{l}\text { HSIL (high-grade squamous } \\
\text { intraepithelial lesion) }\end{array}$ & 4 & $4.34 \%$ \\
\hline $\begin{array}{l}\text { ASC-H (atypical squamous cells, } \\
\text { HSIL cannot be excluded) }\end{array}$ & 10 & $10.86 \%$ \\
\hline AGC (atypical glandular cells) & 2 & $2.17 \%$ \\
\hline $\begin{array}{l}\text { AIS (In situ endocervical } \\
\text { adenocarcinoma) }\end{array}$ & 2 & $2.17 \%$ \\
\hline
\end{tabular}

TABLE 2. Number of HPV-infected patients by age groups

\begin{tabular}{|c|c|c|}
\hline Age (years) & Number of patients & Percentages \\
\hline $18-24$ & 16 & $17.39 \%$ \\
\hline $25-34$ & 48 & $52.17 \%$ \\
\hline $35-44$ & 12 & $13.04 \%$ \\
\hline $45-54$ & 8 & $8.69 \%$ \\
\hline $55-64$ & 8 & $8.69 \%$ \\
\hline
\end{tabular}

Of these patients, $40(43.47 \%)$ came from urban areas and $52(56.52 \%)$ from rural areas.

Because there is a statistically significant association between HPV infection, regardless of viral genotype, with the number of sexual partners throughout life, the history of hormonal contraception and tobacco use, we tried to determine the prevalence of these factors in the study group. Regarding the number of sexual partners, $36(39.13 \%)$ patients assumed 1-2 partners, 40 (43.47\%) of them 3-4 partners, and $16(17.39 \%)$ over 5 partners. We corroborated the data on the number of sexual partners and the environment of origin in table 3 .

TABLE 3. Number of patients with HPV in relation to the number of sexual partners

\begin{tabular}{|c|c|c|c|c|c|c|}
\hline $\begin{array}{l}\text { Nr. partners } \\
\text { Environment }\end{array}$ & \multicolumn{2}{|c|}{$1-2$} & \multicolumn{2}{c|}{$3-4$} & \multicolumn{2}{c|}{$>5$} \\
\hline Urban & 24 & $26.08 \%$ & 16 & $17.39 \%$ & 0 & $0 \%$ \\
\hline Rural & 12 & $13.04 \%$ & 24 & $26.08 \%$ & 16 & $17.39 \%$ \\
\hline
\end{tabular}

Of the total of 92 patients included in the study, 60 (65.21\%) were smokers.

As contraceptives, 56 patients $(60.86 \%)$ were taking, or had taken, estroprogestative contraceptives, and 28 of them $(30.43 \%)$ were using condoms.
Another risk factor for HPV infection cited in the literature is parity. The distribution of parity by age groups is shown in Table 4.

TABLE 4. Distribution of parity by age groups

\begin{tabular}{|c|c|c|c|c|c|c|c|}
\hline Parity & $\begin{array}{c}18-24 \\
\text { ani }\end{array}$ & $\begin{array}{c}25-34 \\
\text { ani }\end{array}$ & $\begin{array}{c}35-44 \\
\text { ani }\end{array}$ & $\begin{array}{c}45-54 \\
\text { ani }\end{array}$ & $\begin{array}{c}55-64 \\
\text { ani }\end{array}$ & \multicolumn{2}{|c|}{ Total } \\
\hline Nulliparous & 9 & 5 & 2 & 0 & 0 & 16 & $17.39 \%$ \\
\hline Primiparous & 4 & 18 & 0 & 2 & 1 & 25 & $27.17 \%$ \\
\hline Multiparous & 3 & 25 & 10 & 6 & 7 & 51 & $55.43 \%$ \\
\hline
\end{tabular}

Of the study group, $28(30.43 \%)$ women were vaccinated with HPV, $64(69.56 \%)$ were not. Of the 28 vaccinated, 19 (20.65\% of the total group) received the bivalent vaccine, and $9(9.78 \%$ of the total group) received the tetravalent vaccine. The number of vaccinated patients by age was according to Table 5 .

TABLE 5. Number of vaccinated patients by age groups

\begin{tabular}{|c|c|c|c|c|c|c|c|c|c|c|}
\hline Age & \multicolumn{2}{|r|}{$18-24$} & \multicolumn{2}{|r|}{$25-34$} & \multicolumn{2}{|c|}{$35-44$} & \multicolumn{2}{|c|}{$45-54$} & \multicolumn{2}{|c|}{$55-64$} \\
\hline Vaccinated & 16 & $17.39 \%$ & 12 & $13.04 \%$ & 0 & $0 \%$ & 0 & $0 \%$ & 0 & $0 \%$ \\
\hline Unvaccinated & 0 & $0 \%$ & 36 & $39.13 \%$ & 12 & $13.04 \%$ & 8 & $8.69 \%$ & & $8.69 \%$ \\
\hline
\end{tabular}

Depending on the clinical symptoms and the results of Babes-Papanicolau (BPN) examinations and the genotyping that all the patients in the study benefited from (these being the inclusion conditions), some of the patients needed: vaginal secretions, colposcopy, biopsy (table 6).

\section{TABLE 6. Types of investigations}

\begin{tabular}{|c|c|c|}
\hline Types of investigations & $\begin{array}{c}\text { Number of } \\
\text { patients }\end{array}$ & Percentages \\
\hline BPN exam & 92 & $100 \%$ \\
\hline HPV genotypes & 92 & $100 \%$ \\
\hline Colposcopy & 41 & $44.56 \%$ \\
\hline Biopsy & 34 & $36.95 \%$ \\
\hline $\begin{array}{c}\text { Vaginals secretions, } \\
\text { cervix cultures }\end{array}$ & 53 & $57.6 \%$ \\
\hline
\end{tabular}

In $34(36.95 \%)$ cases, where the corroboration of the data from BPN, genotyping and colposcopy was inconclusive, cold biopsy or electroresection was performed. The results obtained at the biopsy, corroborated with the age of the patients, are presented in table 7.

TABLE 7. Cellular abnormalities of the cervix according to the age of the patients

\begin{tabular}{|c|c|c|c|c|c|c|c|}
\hline \multirow{2}{*}{$\begin{array}{l}\text { Biopsy } \\
\text { results }\end{array}$} & \multicolumn{5}{|c|}{ Age (years) } & \multirow{2}{*}{\multicolumn{2}{|c|}{ Total }} \\
\hline & $18-24$ & $25-34$ & $35-44$ & 45-54 & $55-64$ & & \\
\hline CIN 1 & - & 1 & 2 & 2 & - & 5 & $5.43 \%$ \\
\hline CIN 2 & - & 12 & 5 & 2 & 4 & 23 & $25 \%$ \\
\hline CIN 3 & - & - & 1 & - & 3 & 4 & $4.34 \%$ \\
\hline $\mathrm{CIS}$ & - & - & 1 & 1 & - & 2 & $2.17 \%$ \\
\hline
\end{tabular}


Of the 34 biopsied patients, 26 underwent surgical treatment. Thus, 9 cauterizations, 11 electroresections, 4 conizations and 2 Wertheim-Meigs radical hysterectomies were performed. The age distribution of the interventions is illustrated in Table 8 .

TABLE 8. Types of surgery in patients with HPV infection

\begin{tabular}{|c|c|c|c|c|c|c|c|}
\hline $\begin{array}{c}\text { Types of } \\
\text { investigations }\end{array}$ & \multicolumn{5}{|c|}{ Age (years) } & \multicolumn{2}{c|}{ Total } \\
\cline { 2 - 8 } & $\mathbf{1 8 - 2 4}$ & $\mathbf{2 5 - 3 4}$ & $\mathbf{3 5 - 4 4}$ & $\mathbf{4 5 - 5 4}$ & $\mathbf{5 5 - 6 4}$ & \multicolumn{2}{|c|}{} \\
\hline Cautery & - & 7 & 2 & - & - & 9 & $9.78 \%$ \\
\hline Electroresection & - & 2 & 3 & 2 & 4 & 11 & $11.95 \%$ \\
\hline Conization & - & - & 1 & - & 3 & 4 & $4.34 \%$ \\
\hline $\begin{array}{c}\text { Wertheim- } \\
\text { Meigs radical } \\
\text { hysterectomy }\end{array}$ & - & - & 1 & 1 & - & 2 & $2.17 \%$ \\
\hline
\end{tabular}

From their statements, all patients were informed, through the family doctor, both about the national screening program for cervical cancer and the availability of vaccination.

\section{DISCUSSIONS}

In the study group, the age distribution of infection with different HPV genotypes had the maximum incidence in the age group 25-34 years (52.17\%). The literature indicates the period of up to 25 years with the highest incidence of HPV infection $(18,19)$. The increase in age with maximum incidence observed in our group is probably related to different sexual behaviors in different population groups, or could be influenced by the selection criteria in the study.

Risk factors for HPV infection include: sexual behavior (early onset of sexual life, large number of sexual partners), large number of pregnancies, smoking, prolonged use of estroprogesterone contraceptives, lack of condom use, poor socioeconomic status, suggestive hereditary-collateral antecedents, immunosuppression (HIV/AIDS, immunosuppressive treatment in transplantation, autoimmune diseases) (20). The increased incidence of cervical cancer in women from certain population groups (South American, African American), confirms that it is influenced not only by sexual behaviors, but also by genetic predisposition $(21,22)$.

In the study group, among the risk factors encountered in a large proportion were smoking, 60 (65.21\%) of patients being smokers. The inclusion of smoking as a risk factor could be explained by the fact that tobacco contains well-known carcinogens, which could have a direct transforming effect on cervical tissues and/or cause immunosuppression, allowing HPV infection to persist and progress. to cancer (23).

The association between HPV infection and hormonal contraception in patients in the study group was good. $56(60.86 \%)$ of them used contraceptives for several years. This association is explained by the interaction of estrogen and progesterone with hormone receptors in cervical tissue. Sex steroid hormones are thought to enhance the expression of HP6E6 and E7 oncogenes, promoting the degradation of p53 tumor suppressor genes and improving the ability of viral DNA to transform cells (24). In the same registry, parity may increase the incidence of HPV infection, 51 of the patients, representing $55.43 \%$ of the study group, were multiparous. Another factor that makes pregnancy a risk factor is immunosuppression that has emerged as a necessity for tolerance to the allogeneic fetus. However, these changes create an increased susceptibility to infections (25-27).

Regarding the number of assumed sexual partners, women from urban areas declared predominantly $1-2$ partners $(26.08 \%)$, and those from rural areas 3-4 partners in $26.08 \%$ of cases. However, considering that we found a relatively large number of genital infections associated with HPV, respectively 53 patients, representing $57.60 \%$ of the total group, and that the percentage of those who used a condom was $30.43 \%$, we consider this inconclusive result.

Reducing morbidity and mortality related to cervical cancer requires the development and expansion of screening programs for cervical pathology. Detection of any HPV (low risk, high risk) can each be associated with ASC-US, LSIL, HSIL, or cervical cancer (28-30). In the study group, which included only patients diagnosed with at least one viral strain, the result of HPV examination included $47.8 \%$ normal results, $2.17 \%$ adenocarcinoma and $50 \%$ modified results, of which ASC-US represented 17 39\%, and HSIL $4.34 \%$.

Screening strategies for cervical neoplasms recommend that all women receive BPN testing after the onset of sexual life. In the case of normal results, testing should be performed at 3-5 years. Vaccinated women should also be tested, as they may contact new strains for which they have not acquired immunity, as well as hysterectomized patients with preoperative $\mathrm{CIN}-2$ or $\mathrm{CIN}-3$, as recurrent cancer may develop in the vaginal arch (31-34).

Screening protocols may include more sensitive techniques than the "classic" BPN examination: col- 
lecting cytology in the liquid medium, associating p16/Ki-67 biomarkers, indicative of the transformation of HPV infections, useful in the management of ASC-US and LSIL cytologies (35-39), and HPV genotyping that identify high-risk strains. Combining HPV genotyping with cytology reduces the mortality rate and extends the screening interval to 5 years with lower costs (40).

HPV genotyping has a role in identifying the risk of residual or recurrent disease after treatment for CIN, but cannot always distinguish between transient infection and chronic infection (41-43).

In the study group were highlighted both high risk strains - 16, 18, 31, 33, 45, 51, 52 - and low risk ones $6,11,42,44,54$. The most common were first strains $16,18,6,11$, as we expected, usually in various combinations. In the 2 causes of adenocarcinoma, as well as in the 4 cases in which conization was performed, strains 16 and 18 were detected in combination with other strains, both high risk and low risk. The results were consistent with data from the literature.

Cellular abnormalities and detected precancerous lesions require further investigation for diagnostic confirmation, follow-up and treatment, depending on the type of lesion diagnosed. In the present study, the use of colposcopy and biopsy was required to establish the diagnosis. Electrosection was used as a method of diagnosis and treatment.

Most HPV infections are transient, self-limiting, and only a small proportion persist and progress to high-quality squamous intraepithelial lesions. It takes 7 to 10 years for a high-risk squamous intraepithelial lesion to progress to cervical cancer (44-46). Most women, especially young ones, get rid of the infection in 1-2 years. It is therefore recommended that intraepielial cervical lesions due to HPV infections be monitored, with the timing of surgery, which is often no longer necessary (47).

In the case of the studied group, the treatment was applied in case of persistence of infection with highly pathogenic strains, or after confirmation of cervical neoplasia. Both cases of adenocarcinoma had a heredo-collateral history of genital neoplasms.

HPV vaccination provides protection not only for dysplasia and cervical cancer, but also for anal, vulvar, oropharyngeal, penile and vaginal neoplasms, or for other benign diseases caused by the virus $(48,49)$. Vaccines currently used (bi, tetra and nonavalent) have already been shown to be effective in developed countries. They can prevent $90 \%$ of benign and ma- lignant lesions due to infection with different HPV genotypes (50).

The vaccines are especially aimed at adolescents aged 9-13 (before the onset of sexual life) and women up to 26 years of age. This vaccination does not provide protection against all existing strains and subtypes, nor does it provide protection against existing infections (51).

In the study group, 28 patients, aged between 18 and 34 (so from the generation in which vaccination programs were implemented at European level) were vaccinated. During this age range, 64 patients were placed, of which $43.75 \%$ were vaccinated.

Vaccination programs differ from country to country, depending on each person's financial strength and specific sexual behaviors. There are countries, such as Sweden (52), where the HPV vaccination program, which includes both girls and boys, has proven its usefulness, both by reducing costs for health services and by reducing the incidence of anogenital, penile and orofringian neoplasms. In developed countries, where vaccination programs have been successfully implemented, there has been a decrease in the incidence of cervical cancer in the unvaccinated population, due to herd immunity (53). In Romania, vaccination programs are in their infancy. There was a reluctance to vaccinate for various reasons, the most common being: belief in their inefficiency, fear of side effects or encouragement of an early onset of sex life. The elimination of these fears can only be achieved through good communication with the authorized staff, mainly with family doctors.

The patients included in the study stated good communication with family doctors. They are directly involved in primary counseling on risk factors and screening for cervical cancer, as well as in HPV vaccination. They also play an important role in health and sex education programs.

\section{CONCLUSIONS}

HPV infection, although widespread, is self-limiting and rarely progresses to different types of cancer.

Cervical cancer can be cured if diagnosed early. Most cases of cervical cancer can be prevented through prevention programs that provide cervical screening for adult women and vaccination against human papilloma virus (HPV).

On the other hand, the dynamic follow-up of cases with precancerous changes of the cervical epithe- 
lium avoids unnecessary interventions, only persistent infections should be operated.

Primary medicine has a special importance in the implementation of screening and prevention policies, Conflict of interest: none declared Financial support: none declared

\section{REFERENCES}

1. Barbera $L$, Thomas $G$. Management of early and locally advanced cervical cancer. Semin Oncol. 2009 Apr;36(2):155-69.

2. Ogembo RK, Gona PN, Seymour AJ, Park HS, Bain PA, Maranda L, Ogembo JG. Prevalence of human papillomavirus genotypes among African women with normal cervical cytology and neoplasia: a systematic review and meta-analysis. PLoS One. $2015 \mathrm{Apr}$ 14:10(4):e0122488.

3. Aleksioska-Papestiev I, Chibisheva V, Micevska M, Dimitrov G. Prevalence of Specific Types of Human Papiloma Virus in Cervical Intraepithelial Lesions and Cervical Cancer in Macedonian Women. Med Arch. 2018 Feb;72(1):26-30.

4. Park SJ, Seo J, Ha SH, Jung GW. Prevalence and determinants of high-risk human papillomavirus infection in male genital warts. Korean J Urol. 2014 Mar;55(3):207-12.

5. Tumban E. A Current Update on Human Papillomavirus-Associated Head and Neck Cancers. Viruses. 2019 Oct 9;11(10):922.

6. Mirghani H, Sturgis EM, Aupérin A, Monsonego J, Blanchard P. Is there an increased risk of cancer among spouses of patients with an HPV-related cancer: A systematic review. Oral Oncol. 2017 Apr;67:138-145.

7. Kuehn BM. Diverse HPV Strains Require Strategic Vaccine Use. JAMA. 2020 Jul 21;324(3):223.

8. Doorbar J. Host control of human papillomavirus infection and disease. Best Pract Res Clin Obstet Gynaecol. 2018 Feb;47:27-41.

9. Egawa N, Doorbar J. The low-risk papillomaviruses. Virus Res. 2017 Mar 2;231:119-127.

10. Adenis A, Dufit V, Douine M, Najioullah F, Molinie V, Catherine D, Kilié O, Thomas N, Deshayes JL, Brousse P, Amor HB, Pignoux R, Carles G, Grenier C, Lacoste V, Cesaire R, Nacher M. The singular epidemiology of HPV infection among French Guianese women with normal cytology. BMC Public Health. 2017 Mar 24;17(1):279.

11. Vinodhini K, Shanmughapriya S, Das BC, Natarajaseenivasan K. Prevalence and risk factors of HPV infection among women from various provinces of the world. Arch Gynecol Obstet. 2012 Mar;285(3):771-7.

12. Liao G, Jiang $X$, She B, Tang $H$, Wang Z, Zhou H, Ma Y, Xu W, Xu H, Chen W, Ji J, Xi M, Chen T. Multi-Infection Patterns and Co-infection Preference of 27 Human Papillomavirus Types Among 137,943 Gynecological Outpatients Across China. Front Oncol. 2020 Apr 7;10:449.

13. Huck N. Prophylaktische Impfung gegen HP-Viren zur Prävention des Zervixkarzinoms : Implementierung der geschlechtsneutralen prophylaktischen Impfung in Deutschland als wirksames Instrument der Prävention [Prophylactic vaccination against HP viruses for the prevention of cervical cancer : Implementation of gender neutral, prophylactic vaccination in Germany as an effective instrument for prevention]. Urologe A. $2018 \mathrm{Jul} ; 57(7): 850-851$.

14. Arbyn M, Xu L, Simoens C, Martin-Hirsch PP. Prophylactic vaccination against human papillomaviruses to prevent cervical cancer and its precursors. Cochrane Database Syst Rev. 2018 May 9;5(5):CD009069.

15. Patel C, Brotherton JM, Pillsbury A, Jayasinghe S, Donovan B, Macartney $\mathrm{K}$, Marshall $\mathrm{H}$. The impact of 10 years of human papillomavirus (HPV) vaccination in Australia: what additional disease burden will a nonavalent vaccine prevent? Euro Surveill. 2018 Oct;23(41):1700737.

16. Garland SM, Kjaer SK, Muñoz N, Block SL, Brown DR, DiNubile MJ, Lindsay BR, Kuter BJ, Perez G, Dominiak-Felden G, Saah AJ, Drury R, Das R, Velicer C. Impact and Effectiveness of the Quadrivalent Human Papillomavirus Vaccine: A Systematic Review of 10 Years of Real-world Experience. Clin Infect Dis. 2016 Aug 15;63(4):519-27. with a very good efficiency, already proven in developed countries where the incidence of cervical cancer has decreased by $90 \%$.

17. Maver PJ, Poljak M. Primary HPV-based cervical cancer screening in Europe: implementation status, challenges, and future plans. Clin Microbiol Infect. 2020 May;26(5):579-583.

18. Manini I, Montomoli E. Epidemiology and prevention of Human Papillomavirus. Ann lg. 2018 Jul-Aug;30(4 Supple 1):28-32.

19. Sendagorta-Cudós E, Burgos-Cibrián J, Rodríguez-Iglesias M. Genital infections due to the human papillomavirus. Enferm Infecc Microbiol Clin. 2019 May;37(5):324-334.

20. Yamaguchi M, Sekine M, Hanley SJB, Kudo R, Hara M, Adachi S, Ueda Y, Miyagi E, Enomoto T. Risk factors for HPV infection and high-grade cervical disease in sexually active Japanese women. Sci Rep. 2021 Feb 3;11(1):2898.

21. Flores BE, Acton GJ. Older Hispanic women, health literacy, and cervical cancer screening. Clin Nurs Res. 2013 Nov;22(4):402-15.

22. Zhang D, Advani S, Huchko M, Braithwaite D. Impact of healthcare access and HIV testing on utilisation of cervical cancer screening among US women at high risk of HIV infection: cross-sectional analysis of 2016 BRFSS data. BMJ Open. 2020 Jan 6;10(1): $\mathrm{e} 031823$.

23. Yorulmaz A, Tamer E, Kulcu Cakmak S. Smoking: Is it a Risk Factor for Common Warts? Curr Health Sci J. 2020 Jan-Mar;46(1):5-10.

24. Roura E, Travier N, Waterboer T, de Sanjosé S, Bosch FX, Pawlita M, Pala V, Weiderpass E, Margall N, Dillner J, Gram IT, Tjønneland A, Munk $C$, et al. The Influence of Hormonal Factors on the Risk of Developing Cervical Cancer and Pre-Cancer: Results from the EPIC Cohort. PLoS One. 2016 Jan 25;11(1):e0147029.

25. von Rango U. Fetal tolerance in human pregnancy--a crucial balance between acceptance and limitation of trophoblast invasion. Immunol Lett. 2008 Jan 15;115(1):21-32.

26. de Castro LL, Lopes-Pacheco M, Weiss DJ, Cruz FF, Rocco PRM. Current understanding of the immunosuppressive properties of mesenchymal stromal cells. J Mol Med (Berl). 2019 May; 97(5):605-618.

27. Díaz-Peña R, de Los Santos MJ, Lucia A, Castro-Santos P. Understanding the role of killer cell immunoglobulin-like receptors in pregnancy complications. J Assist Reprod Genet. 2019 May;36(5):827-835.

28. Rohner E, Edelman C, Sanusi B, Schmitt JW, Baker A, Chesko K, Faherty B, Gregory SM, Romocki LS, Sivaraman V, Nelson JAE, O'Connor S, Hudgens MG, Knittel AK, Rahangdale L, Smith JS. Extended HPV Genotyping to Compare HPV Type Distribution in Self- and Provider-Collected Samples for Cervical Cancer Screening. Cancer Epidemiol Biomarkers Prev. 2020 Dec;29(12):2651-2661.

29. Asciutto KC, Borgfeldt C, Forslund O. 14-type HPV mRNA test in triage of HPV DNA-positive postmenopausal women with normal cytology. BMC Cancer. 2020 Oct 23;20(1):1025.

30. Lv P, Zhao F, Xu X, Xu J, Wang Q, Zhao Z. Correlation between Common Lower Genital Tract Microbes and High-Risk Human Papillomavirus Infection. Can J Infect Dis Med Microbiol. 2019 Nov 22;2019:9678104.

31. Belglaiaa E, Mougin C. Le cancer du col de l'utérus: état des lieux et prévention au Maroc [Cervical cancer: Current situation and management in Morocco]. Bull Cancer. 2019 Nov;106(11):10081022.

32. Woronoff AS, Molinié F, Trétarre B. Mise en place du programme national de dépistage organisé du cancer du col de l'utérus en France [Implementation of National Cervical Cancer Screening Program in France]. Bull Cancer. 2019 Mar;106(3):253-261.

33. Lew JB, Simms KT, Smith MA, Hall M, Kang YJ, Xu XM, Caruana M, Velentzis LS, Bessell T, Saville M, Hammond I, Canfell K. Primary 
HPV testing versus cytology-based cervical screening in women in Australia vaccinated for HPV and unvaccinated: effectiveness and economic assessment for the National Cervical Screening Program. Lancet Public Health. 2017 Feb;2(2):e96-e107.

34. Hall MT, Smith MA, Lew JB, O'Hallahan J, Fentiman G, Neal H, Sage M, Canfell K. The combined impact of implementing HPV immunisation and primary HPV screening in New Zealand: Transitional and long-term benefits, costs and resource utilisation implications. Gynecol Oncol. 2019 Mar;152(3):472-479.

35. Hirth JM, Kuo YF, Starkey JM, Rupp RE, Laz TH, Rahman M, Berenson AB. Regional variations in human papillomavirus prevalence across time in NHANES (2003-2014). Vaccine. $2019 \mathrm{Jul}$ 9;37(30):4040-4046.

36. Gates A, Pillay J, Reynolds D, Stirling R, Traversy G, Korownyk C, Moore A, Thériault G, Thombs BD, Little J, Popadiuk C, van Niekerk D, Keto-Lambert D, Vandermeer B, Hartling L. Screening for the prevention and early detection of cervical cancer: protocol for systematic reviews to inform Canadian recommendations. Syst Rev. 2021 Jan 2;10(1):2.

37. Krishnamurthy A, Ramshankar V. Current Status and Future Perspectives of Molecular Prevention Strategies for Cervical Cancers. Indian J Surg Oncol. 2020 Dec;11(4):752-761.

38. Wu Y, Zhao J, Hu J, Wu XW, Zhu LR. Significance of p16/Ki-67 double immunocytochemical staining in cervical cytology ASCUS, LSIL, and ASC-H. Zhonghua Fu Chan Ke Za Zhi. 2017 Nov 25;52(11):734-739.

39. Frega A, Pavone M, Sesti F, Leone C, Bianchi P, Cozza G, Colombrino C, Lukic A, Marziani R, De Sanctis L, Delli Carpini G, Caserta D, Ciavattini A. Sensitivity and specificity values of high-risk HPV DNA, p16/ki-67 and HPV mRNA in young women with atypical squamous cells of undetermined significance (ASCUS) or low-grade squamous intraepithelial lesion (LSIL). Eur Rev Med Pharmacol Sci. 2019 Dec;23(24):10672-10677.

40. Bhatla N, Singhal S. Primary HPV screening for cervical cancer. Best Pract Res Clin Obstet Gynaecol. 2020 May;65:98-108.

41. Clarke MA, Gradissimo A, Schiffman M, Lam J, Sollecito CC, Fetterman B, Lorey T, Poitras N, Raine-Bennett TR, Castle PE, Wentzensen N, Burk RD. Human Papillomavirus DNA Methylation as a Biomarker for Cervical Precancer: Consistency across 12 Genotypes and Potential Impact on Management of HPV-Positive Women. Clin Cancer Res. 2018 May 1;24(9):2194-2202.

42. Demarco M, Hyun N, Carter-Pokras O, Raine-Bennett TR, Cheung L, Chen X, Hammer A, Campos N, et al. A study of type-specific HPV natural history and implications for contemporary cervical cancer screening programs. EClinicalMedicine. $2020 \mathrm{Apr}$ 25;22:100293.

43. Ibáñez R, Roura E, Monfil L, Rodríguez LA, Sardà M, Crespo N, Pascual A, Martí C, Fibla M, Gutiérrez C, Lloveras B, Oliveras G, Torrent A, Català I, Bosch FX, Bruni L, de Sanjosé S. Long-term protection of HPV test in women at risk of cervical cancer. PLOS One. 2020 Aug 27;15(8):e0237988.

44. de Martel C, Plummer M, Vignat J, Franceschi S. Worldwide burden of cancer attributable to HPV by site, country and HPV type. Int $J$ Cancer. 2017 Aug 15;141(4):664-670.

45. Lekoane KMB, Kuupiel D, Mashamba-Thompson TP, Ginindza TG. Evidence on the prevalence, incidence, mortality and trends of human papilloma virus-associated cancers in sub-Saharan Africa: systematic scoping review. BMC Cancer. 2019 Jun 11;19(1):563.

46. Serrano B, Brotons M, Bosch FX, Bruni L. Epidemiology and burden of HPV-related disease. Best Pract Res Clin Obstet Gynaecol. 2018 Feb;47:14-26.

47. Kleinsorge F, Schmidmayr M. Humane Papillomavirusinfektion bei Frauen : Diagnostik, Therapie und Bedeutung der Impfung [HPV infection in women : Diagnostics, treatment and the relevance of vaccination]. Urologe A. 2018 Dec;57(12):1445-1451.

48. Hirth J. Disparities in HPV vaccination rates and HPV prevalence in the United States: a review of the literature. Hum Vaccin Immunother. 2019;15(1):146-155.

49. Cheng L, Wang Y, Du J. Human Papillomavirus Vaccines: An Updated Review. Vaccines (Basel). 2020 Jul 16;8(3):391.

50. Wieland U, Kreuter A. Prävention HPV-induzierter Erkrankungen durch prophylaktische Impfung [Prevention of HPV-induced diseases by prophylactic vaccination]. Hautarzt. 2021 Feb;72(2):106-113.

51. Bergman H, Buckley BS, Villanueva G, Petkovic J, Garritty C, Lutje V, Riveros-Balta AX, Low N, Henschke N. Comparison of different human papillomavirus (HPV) vaccine types and dose schedules for prevention of HPV-related disease in females and males. Cochrane Database Syst Rev. 2019 Nov 22;2019(11):CD013479.

52. Wolff E, Elfström KM, Haugen Cange H, Larsson S, Englund H, Sparén P, Roth A. Cost-effectiveness of sex-neutral HPV-vaccination in Sweden, accounting for herd-immunity and sexual behaviour. Vaccine. 2018 Aug 16;36(34):5160-5165.

53. Spinner C, Ding L, Bernstein DI, Brown DR, Franco EL, Covert C, Kahn JA. Human Papillomavirus Vaccine Effectiveness and Herd Protection in Young Women. Pediatrics. 2019 Feb;143(2):e20181902. 